\title{
Surgical Termination of Pregnancy as a Cause of Rhesus Sensitization
}

\author{
J. GELLÉN,* M.D. ; Z. KOVÁCS,† M.D. ; F. E. SZONTÁGH,ł M.D. ; D. BODA,§ M.D.
}

Brit. med. F., 1965, 2, 1471-1472

The immunizing effects of spontaneous or induced abortions when there is foetal-maternal blood-group incompatibility are well known (Levine, 1943 ; Sauer and Kulich, 1964). Though there are a large number of reports of foetal erythrocytes in the maternal circulation after surgical intervention in full-term pregnancies (Goodall et al., 1958; Zipursky et al., 1959 ; Kleihauer et al., 1957 ; Apley et al., 1961 ; Durkin and Finn, 1961 ; Finn et al., 1963 ; Brown, 1963 ; Freese and Titel, 1963 ; Keenan and Pearse, 1963), there are few reports of findings during termination of pregnancy in its early stages. We have therefore investigated this problem.

\section{Material and Methods}

Our investigations were carried out on 56 healthy women who underwent operative termination of their pregnancies in the second and third months on social grounds. The number of erythrocytes carrying foetal-type haemoglobin (F.E.) was determined just before operation and 4 to 12 hours after operation. A group of non-pregnant women who had undergone diagnostic curettage of the uterus served as control. Erythrocytes containing foetal-type haemoglobin were demonstrated by the acid-elution method of Kleinhauer et al. (1957) and of Zipursky et al. (1959). The $\mathrm{pH}$ of eluting solution was 3.6, since Zipursky et al. have stated that at the $\mathrm{pH}$ range 3.2-3.6 this technique is especially sensitive, even in cases with relatively low haemoglobin concentrations.

In a preliminary study we examined the erythrocytes of foetuses between 2 and 3 months of age, both in pure preparations and mixed with adult blood of the same blood group. We found that the foetal erythrocytes contained a derivative of haemoglobin that was resistant to elution by acid. Furthermore, these erythrocytes could be stained less intensely than the F.E.s of the newborn, though after elution they stained much more strongly than the erythrocytes containing adult-type haemoglobin. In some cases a reticulocyte count was performed simultaneously.

The blood smears were examined under the $\times 900$-power magnification of the microscope. Smears of one-cell thickness were scanned for five minutes, and the number of F.E.s counted in this period recorded (Zipursky et al., 1962 ; Kristoffersen et al., 1962). We must point out that the number of F.E.s counted in a five-minute scan depends on the degree of dilution. Zipursky (1963), and most investigators after him, used smears of diluted blood. On the other hand, we have used smears of whole blood, and this may account for the higher values found in our control subjects.

\section{Results}

We divided our 56 patients into two groups-those up to the second month of pregnancy and those up to the third month (see Table). The average number of F.E.s found in the first \footnotetext{
* Research Assistant, Department of Obstetrics and Gynaecology,

t Research Assistant, Department of Paediatrics, University Medical School, Szeged, Hungary.

₹ Professor and Director, Department of Obstetrics and Gynaecology, University Medical School, Szeged, Hungary.

$\checkmark$ Professor and Director, Department of Paediatrics, University Medical School, Szeged, Hungary.
}

group before operation was 12.1. Four to 12 hours after operation this number had increased to 24.5 . In seven cases the number had actually decreased, while in another three no change could be detected. The average number of F.E.s found in the second group was 10.15 , and after operation this increased to 22.3. In three cases there was a decrease in the number of cells found, while in one case there was no change. Analysis by Student's test showed that this increase was significant in both groups. There was no appreciable difference between the two groups according to the length of pregnancy (see Chart). In seven cases in which the reticulocyte count was performed no correlation between this and the changes in the F.E. count could be found. In the control group no significant alteration of the F.E. count was found either before or after operation. In the second group, comprising 10 men, 8 to 12 FE.s could be detected in the eluted smear during the five-minute examination.

Elevation of F.E. Count in the Maternal Blood, Interruptions and Uterine Curettage

\begin{tabular}{|c|c|c|c|c|c|c|}
\hline \multirow{4}{*}{ · } & \multicolumn{4}{|c|}{ Stage of Gestation } & \multirow{2}{*}{\multicolumn{2}{|c|}{$\begin{array}{c}\text { Non-pregnant } \\
(10 \text { Cases })\end{array}$}} \\
\hline & \multicolumn{2}{|c|}{$\begin{array}{l}\text { Second Month } \\
\text { (36 Cases) }\end{array}$} & \multicolumn{2}{|c|}{$\begin{array}{l}\text { Third Month } \\
\text { (20 Cases) }\end{array}$} & & \\
\hline & Before & $\begin{array}{c}4-12 \mathrm{hr} . \\
\text { After }\end{array}$ & Before & $\begin{array}{l}4-12 \mathrm{hr} . \\
\text { After }\end{array}$ & Before & After \\
\hline & \multicolumn{4}{|c|}{ Interruption } & \multicolumn{2}{|c|}{ Curettage } \\
\hline $\begin{array}{l}\text { Average number of F.E.s } \\
\text { counted within } 5 \\
\text { minutes in eluted } \\
\text { smears }\end{array}$ & $\begin{array}{r}12 \cdot 1 \\
\pm 8 \cdot 4\end{array}$ & $\begin{array}{r}24.5 \\
\pm 21.0\end{array}$ & $\begin{array}{r}10.1 \\
\pm 9.5\end{array}$ & $\begin{array}{r}22 \cdot 3 \\
\pm 14.9\end{array}$ & $\begin{array}{r}13.3 \\
\pm 4 \cdot 0\end{array}$ & $\begin{array}{r}14 \cdot 0 \\
\pm 4 \cdot 1\end{array}$ \\
\hline Significance of difference & \multicolumn{2}{|c|}{$\mathbf{P}<0.01$} & \multicolumn{2}{|c|}{$P<0.05$} & \multicolumn{2}{|c|}{$P>0.05$} \\
\hline
\end{tabular}

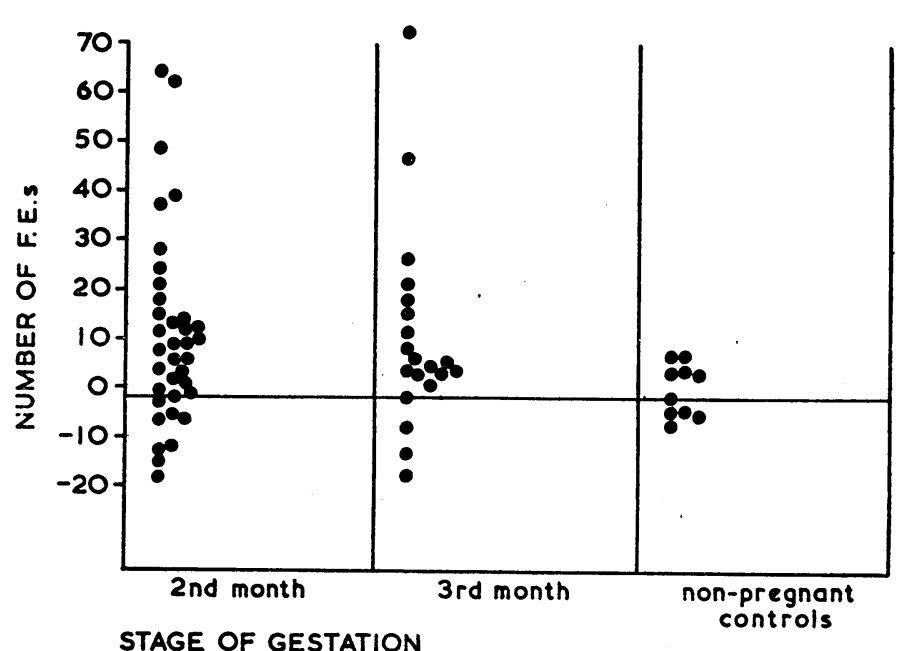

Difference in F.E. counts before and after operative termination of pregnancy and uterine curettage.

\section{Discussion}

There are now a considerable number of papers dealing with the way in which erythrocytes containing foetal-type haemoglobin may pass into the maternal circulation during pregnancy and notably during delivery, particularly during operative intervention (Colebatch et al., 1956; Wimhöfer et al., 1962 ; 
Zilliacus, 1963 ; Queenan and Nakamoto, 1964). On the other hand, to our knowledge nobody has yet described the transfer of F.E.s into the maternal circulation during operative termination of pregnancy at an early stage, and our survey was designed to answer this question. Our results plainly indicate that the number of F.E.s in the circulation rises significantly under these conditions. A finding of interest was that some F.E.s can be detected in the blood both of non-pregnant women and of men, though it must be pointed out that the $\mathrm{pH}$ of the buffer solution we used was higher than that originally described, and this may have had some influence on the number of eluted cells.

Thus erythrocytes containing foetal-type haemoglobin also contain a considerable amount of adult-type haemoglobin. In this connexion it must be remembered that in whole blood tested by the alkali-denaturation method the concentration of foetaltype haemoglobin amounts to at least $1 \%$ in normal people.

There are at least two possibilities to explain the raised F.E. count after operative termination of pregnancy. First, any mechanism that is responsible for producing and for mobilizing foetal-type haemoglobin may rapidly become activated. Secondly, foetal erythrocytes may pass from the embryo into the maternal circulation through the injured endometrial vessels. Some authors consider that the erythropoietic system of the adult is potentially capable of producing foetal-type haemoglobin as well (Zipursky et al., 1962). It is also possible that the production of foetal-type haemoglobin during pregnancy might be enhanced, though this is uncertain. Nevertheless, the relatively short time that elapses between operative termination of pregnancy and the finding of F.E.s in the maternal bloodstream seems to support the second possibility rather than the first one. The finding that there was no rise in F.E.s in non-pregnant women who underwent curettage of the uterus seems to suggest that the mechanism is specific to pregnancy.

If the mechanism of sensitization is as we have postulated, it still remains to be determined to what extent this microtransfusion contributes to the sensitization of pregnant women when foetal-maternal rhesus incompatibility is present. As Levine (1944) and Wiener (1948) have pointed out, even 0.05 to
$0.06 \mathrm{ml}$. of foetal blood may be sufficient to sensitize the mother, and on the basis of our findings it is likely that the amount of foetal blood entering the maternal circulation during the artificial termination of pregnancy is considerably more than this. Though more work on this matter is needed to prove our hypothesis, the possibility of maternal sensitization by artificial termination of pregnancy in rhesus incompatibility must always be borne in mind, particularly in first pregnancies.

\section{Summary}

We have shown that after surgical termination of pregnancy at 2-3 months the number of erythrocytes containing foetaltype haemoglobin in the maternal circulation is significantly raised. This suggests that termination of pregnancy may have an important immunizing role in foetal-maternal rhesus incompatibility.

\section{REFERENCES}

Apley, J., Colley, P. A. N., and Fraser, I. D. (1961). Lancet, 1, 1375. Apley, Je Colley, P. A. N., and Brit. med.

Brown, Elest. Aust., 2, 209.

Durkin, C. M., and Finn, R. (1961). Lancet, 2, 100.

Finn, R., Harper, D. T., Stallings, S. A., and Krevans, J. R. (1963). Transfusion (Philad.), 3, 114

Preese, U. E., and Titel, J. H. (1963). Obstet. and Gynec., 22, 527. Goodall, H. B., Graham, F. S., Miller, M. C., and Cameron, C. (1958). f. clin. Path., 11, 251.

Keenan, H., and Pearse, W. H. (1963). Amer. f. Obstet. Gynec., 86, 1096.

Kleihauer, E., Braun, H., and Betke, K. (1957). Klin. Wschr., 35, 637. Kristofersen, K. Jensen, K. G., and Felbo, M. (1962). Dan. med. Bull., 9, 203.

Levine, P. (1943). 7. Hered., 34, 71.

- (1944). Arch. Path., 37, 83.

Queenan, J. T., and Nakamoto, M. (1964). Obstet. and Gynec., 23, 392 .

Sauer, J., and Kulich, Vl. (1964). Zbl. Gynäk., 86, 1596.

Wiener, A. S. (1948). Amer. F. Obstet. Gynec., 56, 717.

Wimhöfer, H., Schneider, J., and Leidenberger, F. (1962). Geburtsh. u. Frauenheilk., 22,589 .

illiacus, H. (1963). Amer. 7. Obstet. Gynec., 86, 1093.

Zipursky, A. (1963). Lancet, 2, 489.

Zipursky, A. (1963). Lancet, 2, 489. Hull, A., White, F. D., and Israels, L. G. (1959). Ibid., 1, 451. Pediatrics, 30, 262.
Robinson et al. (1964) have suggested that the excretion of large amounts of the dopamine metabolites, homovanillic acid and 3-methoxytyramine, may indicate that a phaeochromocytoma is malignant. Their suggestion was based on the finding of abnormal urinary excretion of these substances in only one out of 36 phaeochromocytoma patients studied, this case also being the only malignant one in the series. Two additional cases of malignant phaeochromocytoma with elevated urinary homovanillic acid have been reported (Sankoff and Sourkes, 1963 ; Ruthven and Sandler, 1964). On the other hand, an increased urinary excretion of dopamine was found some years ago by Weil-Malherbe (1956) in a presumably benign case of phaeochromocytoma, and both dopamine and homovanillic acid have subsequently been found to be increased in two additional benign cases (Page and Jacoby, 1964 ; Ruthven and Sandler, 1964).

* Experimental Therapeutics Branch, National Heart Institute, National Institutes of Health, Bethesda, Maryland.

† Visiting Scientist from Tohoku University School of Medicine, Sendai, Japan.
We wish to report the results of measurements of urinary homovanillic acid in five patients with malignant and 10 with benign phaeochromocytoma, studied during the past year. In

\begin{tabular}{|c|c|c|c|}
\hline Condition & Case & Age & $\begin{array}{l}\text { Urinary H.V.A. } \\
\text { (mg./24 hr.) }\end{array}$ \\
\hline $\begin{array}{l}\text { Malignant } \\
\text { phaeochromocytoma }\end{array}$ & $\begin{array}{l}1 \\
2 \\
3 \\
4 \\
5\end{array}$ & $\begin{array}{l}12 \\
12 \\
12 \\
19 \\
31\end{array}$ & $\begin{array}{r}5 \cdot 1 \\
4 \cdot 0 \\
3 \cdot 1 \\
3 \cdot 3 \\
10 \cdot 2\end{array}$ \\
\hline Six normal adult subject & $\begin{array}{r}1 \\
2 \\
3 \\
4 \\
5 \\
6 \\
7 \\
8 \\
9 \\
10\end{array}$ & $\begin{array}{l}24 \\
49 \\
53 \\
16 \\
12 \\
38 \\
55 \\
39 \\
29 \\
42\end{array}$ & $\begin{array}{c}3 \cdot 3 \\
2 \cdot 1 \\
7 \cdot 0 \\
3 \cdot 3 \\
5 \cdot 6 \\
3 \cdot 3 \\
6 \cdot 1 \\
5 \cdot 3 \\
6 \cdot 4 \\
3 \cdot 5 \\
3 \cdot 4 \cdot 7 \cdot 5\end{array}$ \\
\hline
\end{tabular}

